\title{
DETECÇÃO DO ENTUPIMENTO EM GOTEJADORES APLICANDO PERCOLADO DE ATERRO SANITÁRIO DILUÍDO
}

\author{
Hudson Salatiel Marques Vale* \\ Rafael Oliveira Batista** \\ Danniely de Oliveira Costa*** \\ Luis César de Aquino Lemos Filho***** \\ Delfran Batista dos Santos ${ }^{* * * * *}$ \\ Paulo César Moura da Silva*******
}

RESUMO: O uso planejado de lixiviado de resíduo sólido urbano é uma estratégia voltada à conservação do meio ambiente, servindo como fonte de água e nutrientes para a vegetação que protege as células do aterro sanitário dos efeitos da erosão. $\mathrm{O}$ presente trabalho objetivou analisar a alteração dos indicadores de redução da vazão relativa (RQR), redução parcial de vazão (RPQ) e aumento parcial de vazão (APQ) em unidades gotejadoras operando com percolado de aterro sanitário, sob pressões de serviço. O experimento foi montado com dois fatores, sendo o primeiro fator os três tipos de gotejadores (Plastro Hydrodrip Super, Netafim Tiran e Netafim PCJ-CNJ) e o segundo fator as quatro pressões de serviço $(70,140,210$ e $280 \mathrm{kPa})$ em três repetições. A vazão dos emissores foi determinada a cada $20 \mathrm{~h}$, até completar 160 $\mathrm{h}$ de operação das unidades gotejadoras. Os dados foram submetidos à análise de regressão. Os resultados indicaram que os gotejadores não autocompensantes (Plastro Hydrodrip Super e Netafim Tiran) apresentaram maiores níveis de entupimento em relação ao gotejador autocompensante (Netafim PCJ-CNJ). Houve atenuação do entupimento quando o gotejador Netafim PCJ-CNJ operou com percolado diluído sob as pressões de serviço de 70 e $140 \mathrm{kPa}$.

\section{PALAVRAS-CHAVE: Desempenho hidráulico; Emissores; Resíduo líquido.}

\footnotetext{
Mestre em Manejo de Solo e Água, doutorando do Programa de Pós-Graduação em Manejo de Solo e Água da Universidade Federal Rural do Semi-árido (UFERSA), Brasil.

** Doutor em Engenharia Agrícola, docente do Programa de Pós-Graduação em Manejo de Solo e Água da Universidade Federal Rural do Semi-árido (UFERSA), Brasil. E-mail: rafaelbatista@ufersa.edu.br

*** Mestra em Manejo de Solo e Água, doutoranda do Programa de Pós-Graduação em Manejo de Solo e Água da Universidade Federal Rural do Semi-árido (UFERSA), Brasil.

**** Doutor em Engenharia Agrícola, docente do Programa de Pós-Graduação em Manejo de Solo e Água da Universidade Federal Rural do Semi-árido (UFERSA), Brasil.

****** Doutor em Engenharia Agrícola, docente do Programa de Pós-graduação em Produção Vegetal no Semiárido do Instituto Federal Baiano (IFBAIANO), Brasil.

${ }^{* * * * * *}$ Doutor em Recursos Naturais, docente do Curso de Especialização em Geoprocessamento e Georreferenciamento da Universidade Federal Rural do Semi-árido (UFERSA), Brasil.
} 


\section{DETECTION OF CLOGGING IN SPRINKLERS BY THE APPLICATION OF DILUTED SANITARY LANDFILL PERCOLATE}

ABSTRACT: The planned use of urban solid residue leaching is a strategy for the conservation of the environment. It becomes a source of water and nutrients for vegetation that protects the cells of sanitary landfill from erosion. Current study analyzes alterations of reduction indicators of relative discharge, partial discharge reduction and partial discharge increase in sprinklers using sanitary landfill percolate under pressure. The experiment comprised two factors: the first factor consisted of three types of sprinklers (Plastro Hydrodrip Super, Netafim Tiran and Netafim $P C J-C N J)$ and the second factor consisted of four types of pressure (70, 140, 210 and $280 \mathrm{kPa}$ ), with three replications. Discharge of emitters was determined every $20 \mathrm{~h}$, till $160 \mathrm{~h}$, for the operation of sprinkler units. Data were submitted to regression analysis. Results showed that non auto-compensation sprinklers (Plastro Hydrodrip Super and Netafim Tiran) had the highest clogging rates when compared to the auto-compensation sprinkler (Netafim PCJ-CNJ). Clogging decreased when diluted percolate was employed in sprinkler Netafim PCJ-CNJ under 70 and $140 \mathrm{kPa}$.

KEY WORDS: Hydraulic performance; Emitters; Liquid residue.

\section{INTRODUÇÃO}

As alternativas consideradas ambientalmente adequadas para destinação/disposição de resíduos sólidos urbanos (RSU) são a disposição em aterro, reutilização, reciclagem, compostagem, recuperação e aproveitamento energético (GOMES et al., 2015).

Nos países em desenvolvimento os aterros comuns, sanitários e controlados são muito utilizados na destinação/disposição de RSU tendo como principias problemas o prazo de uso limitado, a produção de percolado com alto potencial de contaminação do solo e das águas superficiais e subterrâneas e a liberação de resíduos gasosos para atmosfera causadores de poluição e aquecimento global (EL-SALAM; ABU-ZUID, 2015).

Segundo Moody e Townsend (2017), o percolado é uma substância complexa resultante de produtos químicos, matéria orgânica, sais inorgânicos, poluentes orgâ- 
nicos e metais pesados, cada um em concentrações que variam com base nos processos físicos (intemperismo), químicos (dessorção) e microbiológicos (degradação de resíduos orgânicos) que ocorrem dentro do aterro sanitário.

O percolado proveniente de aterros sanitários é um subproduto de interesse na produção de biomassa vegetal e que apresenta alta variabilidade composicional, destacando-se, também, a presença de nutrientes importantes como nitrogênio, fósforo e potássio (MATOS et al., 2013), apresentando potencial para a produção de gramíneas, que podem ser empregadas na proteção externa das células do aterro sanitário contra os efeitos da erosão em período chuvoso (COELHO et al., 2015).

Este potencial é evidenciado no trabalho de Coelho et al. (2015), onde foi produzido capim elefante (PennisetumpurpureumSchum.) com $60 \mathrm{~mm}$ de percolado de aterro sanitário diluído em água de abastecimento, ao longo de 160 dias, obtendo-se plantas com altura média de $2,86 \mathrm{~m}$. Por outro lado, em outro estudo de Coelho et al. (2016), é alertado sobre o risco potencial de contaminação do solo por metais pesados, caso o percolado seja aplicado com dosagem excessiva.

Os métodos de irrigação interferem, diretamente, na contaminação do meio ambiente, particularmente quando as águas residuárias, com presença de material fecal, são utilizadas para fins agrícolas e florestais. Neste sentido, a irrigação localizada se destaca em relação à irrigação por aspersão e por superfície, devido ao uso mais eficiente da água e pelos menores riscos de contaminação microbiológica do solo, mananciais, planta, produto agrícola, trabalhadores e atmosfera (LI; WEN, 2016).

Contudo, um dos grandes problemas associado à utilização de águas residuárias através da irrigação por gotejamento consiste na modificação da vazão pelo entupimento parcial ou total dos emissores, prejudicando a uniformidade de aplicação do efluente (FERNANDES et al., 2014; MARQUES et al., 2016; MESQUITA et al., 2016a; b; SILVA et al., 2016; CUNHA et al., 2017).

Mesquita et al. (2016a; b) operaram unidades gotejadoras com percolado de aterro sanitário diluído, durante $160 \mathrm{~h}$; ao final do estudo constataram que o gotejador não autocompensante foi o mais suscetível ao entupimento, por biofilme constituído de suspensos, bactérias, vermes e protozoários, em relação aos gotejadores autocompensantes. 
A minimização do entupimento de gotejadores por biofilme pode ser alcançada, aumentando-se a pressão de serviço do sistema de irrigação. No trabalho de Silva et al. (2016), com unidades gotejadoras aplicando águas residuária da castanha de caju, durante 160 h, foi evidenciada a minimização na formação de biofilme com pressões de serviço a partir de $140 \mathrm{kPa}$.

Diante do exposto, objetivou-se com este trabalho analisar o comportamento de indicadores de detecção de obstrução em unidades gotejadoras operando com percolado de aterro sanitário diluído sob pressões de serviço.

\section{MATERIAL E MÉTODOS}

Este trabalho foi realizado no período de 27 de novembro de 2013 a 06 de janeiro de 2014, na Unidade Experimental de Reuso de Água (UERA), ocupando uma área de $793 \mathrm{~m}^{2}$, localizada na Universidade Federal Rural do Semi-Árido (UFERSA), em Mossoró (RN) (5'12'27”' S e 37¹9'21" W na altitude de 26 m).

O percolado utilizado no experimento foi proveniente das células do aterro sanitário de Mossoró (RN) e encontrava-se armazenado no reservatório da estação de bombeamento do aterro. As coletas do percolado foram realizadas por meio de dois motores de partida de $1 \mathrm{cv}$, os quais recalcavam o resíduo líquido do tanque para uma caixa impermeabilizada de fibra de vidro com capacidade para 1,0 $\mathrm{m}^{3}$, sendo encaminhado, em seguida, para o local do experimento na UERA, onde era depositado em dois reservatórios de polietileno com capacidade para $0,56 \mathrm{~m}^{3}$ cada.

Para a condução dos ensaios, montou-se uma bancada experimental em alvenaria nas dimensões de 2,0 $\mathrm{m}$ de largura por 8,0 $\mathrm{m}$ de comprimento, dotada de um reservatório com capacidade para $5,0 \mathrm{~m}^{3}$, construído à jusante da bancada, composta, ainda, por quatro unidades gotejadoras, duas bombas centrífugas (sendo uma de $0,5 \mathrm{cv}$ e a outra de $1,0 \mathrm{cv}$ ) acionadas, simultaneamente, e dois filtros de tela com aberturas de $130 \mu \mathrm{m}$, conforme ilustrado na Figura 1. 


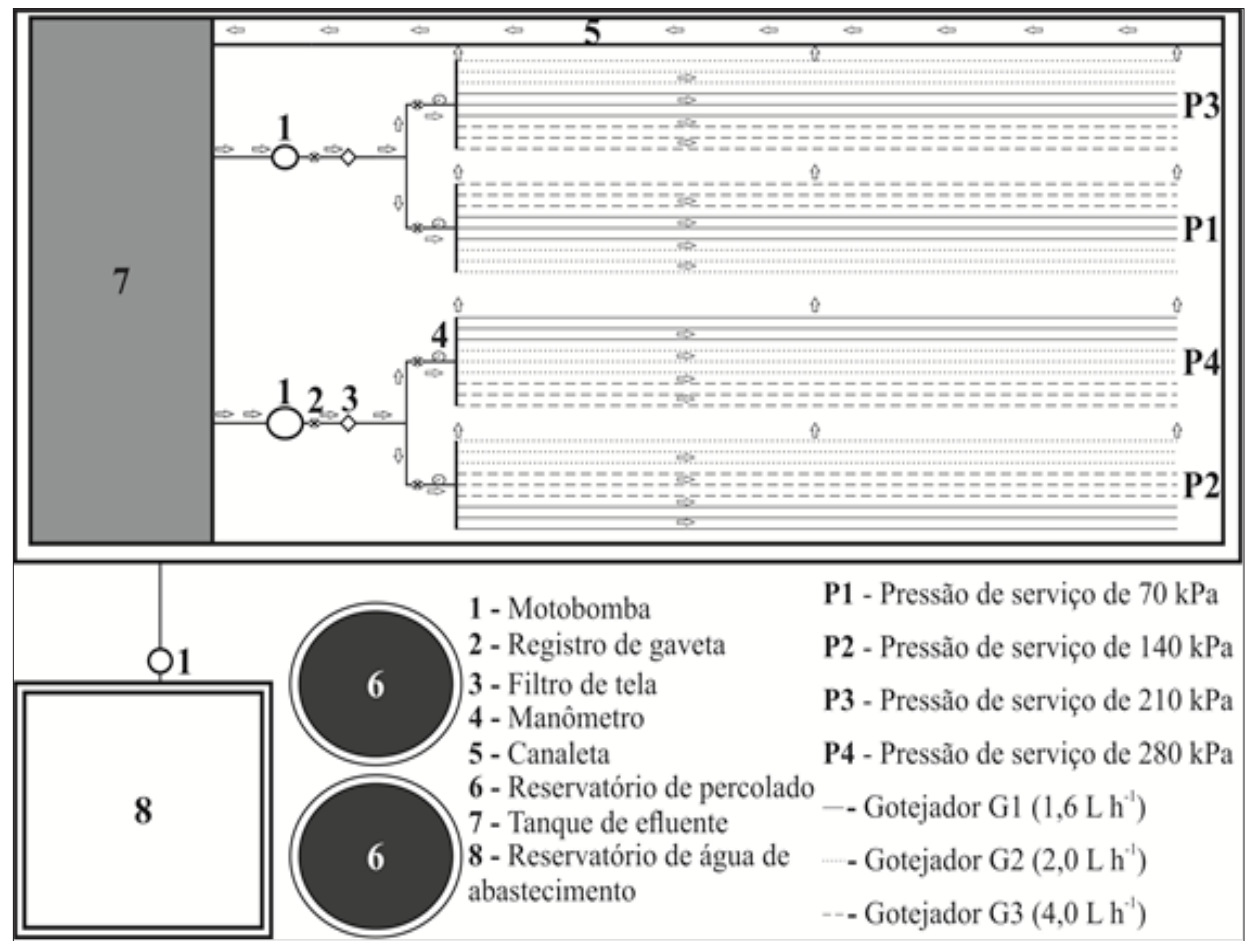

Figura 1. Ilustração esquemática do sistema experimental monitorado na presente pesquisa.

Cada unidade gotejadora possuía um manômetro analógico de glicerina da marca GE CI2.5 graduado de 0 a $400 \mathrm{kPa}$, um registro de gaveta para controle das pressões de serviço $(70,140,210$ e $280 \mathrm{kPa})$ e uma linha de derivação de PVC com diâmetro nominal de $32 \mathrm{~mm}$, onde foram inseridos nove conectores para junção de nove linhas laterais de polietileno de $8 \mathrm{~m}$ de comprimento, dotadas de três tipos de gotejadores (Tabela 1). 
Tabela 1. Características dos gotejadores $(G)$ utilizados nos ensaios experimentais, destacando o fabricante (F), o dispositivo de autocompensação (DA), a vazão nominal $(\mathrm{Q})$, a área de filtragem (A), o comprimento do labirinto (L), o coeficiente de variação de fabricação $\left(\mathrm{CV}_{\mathrm{f}}\right)$, a faixa de pressão recomendada (P) e o espaçamento entre emissores (EE)

\begin{tabular}{|c|c|c|c|c|c|c|c|c|}
\hline G & $\mathrm{F}$ & $\mathrm{DA}^{(1)}$ & $\begin{array}{l}\mathrm{Q}^{(2)} \\
\left(\mathrm{L} \mathrm{h}^{-1}\right)\end{array}$ & $\begin{array}{c}\mathrm{A} \\
\left(\mathrm{mm}^{2}\right)\end{array}$ & $\begin{array}{c}\mathrm{L} \\
(\mathrm{mm})\end{array}$ & $\begin{array}{l}\mathrm{CV}_{\mathrm{f}}^{*} \\
(\%)\end{array}$ & $\begin{array}{c}\mathrm{P*} \\
(\mathrm{kPa})\end{array}$ & $\begin{array}{l}\mathrm{EE}^{*} \\
(\mathrm{~m})\end{array}$ \\
\hline G1 & $\begin{array}{l}\text { Plastro Hydrodrip } \\
\text { Super }\end{array}$ & Não & 1,65 & $4,0^{(2)}$ & $37^{(2)}$ & \pm 5 & $60-150$ & 0,30 \\
\hline G2 & Netafim Tiran & Não & 2,00 & $70,0^{(1)}$ & $75^{(1)}$ & \pm 7 & $100-300$ & 0,40 \\
\hline G3 & Netafim PCJ-CNJ & Sim & 4,00 & $2,0^{(1)}$ & $35^{(1)}$ & \pm 7 & $50-400$ & 0,70 \\
\hline
\end{tabular}

Nota: ${ }^{(1)} \mathrm{e}^{(2)}$ Informações obtidas nos catálogos dos fabricantes e informações medidas com auxílio de um paquímetro digital tendo precisão de $0,01 \mathrm{~mm}$. CNJ - Sistema anti-drenante.

Como o valor da salinidade do percolado de aterro sanitário é elevada, efetuou-se a sua diluição em água de poço na proporção de 1:3 (uma parte de percolado de aterro sanitário para três partes de água de poço), com o intuito de manter os níveis de salinidade do efluente próximos de 3,0 $\mathrm{dS} \mathrm{m}^{-1}$, atendendo, assim, a Resolução n ${ }^{\circ} 2$ do COEMA (CEARÁ) que estabelece padrões de reúso da água para fins agrícolas, florestais e ambientais.

Nas 36 linhas laterais das unidades gotejadoras foram fixados dez gotejadores equidistantes entre si, por linha lateral, para a detecção do nível de entupimento. As unidades gotejadoras funcionaram, em média, cinco horas por dia, sete dias por semana até completar $160 \mathrm{~h}$.

A cada 20 h de operação das unidades gotejadoras mediu-se a vazão dos dez gotejadores selecionados por linha lateral, coletando-se o volume aplicado de efluente, durante três minutos, conforme recomendado pela NBR ISO 9261 (ABNT, 2006). Para interpretação dos dados de vazão, utilizou-se a redução da vazão relativa (RQR) descrita pela Equação 1.

$$
\mathrm{RQR}=100 \cdot\left(\frac{\mathrm{q}_{\mathrm{i}}-\mathrm{q}_{\mathrm{a}}}{\mathrm{q}_{\mathrm{i}}}\right)
$$

em que: 


$$
\begin{aligned}
& \text { RQR - redução da vazão relativa, \%; } \\
& \mathrm{q}_{\mathrm{i}} \text { - vazão inicial, } \mathrm{L} \mathrm{h}^{-1} ; \mathrm{e} \\
& \mathrm{q}_{\mathrm{a}} \text { - vazão atual, } \mathrm{L} \mathrm{h}^{-1} \text {. }
\end{aligned}
$$

Para completar a avaliação dos níveis de obstrução dos gotejadores, empregaram-se, ainda, os indicadores aumento parcial de vazão (APQ) e redução parcial de vazão (RPQ), recomendados por Ravina et al. (1992) para avaliação de gotejadores operando com água residuária. Os referidos autores consideram gotejadores parcialmente entupidos (RPQ) aqueles que apresentam redução da vazão inicial de 10 a 49\%, e gotejadores com aumento parcial de vazão (APQ) aqueles que apresentam aumento da vazão inicial superior a $10 \%$.

$\mathrm{O}$ experimento foi montado com dois fatores, sendo o primeiro fator os três tipos de gotejadores (G1 - Plastro Hydrodrip Super, G2 - Netafim Tiran e G3 - Netafim $P C J-C N J)$ e o segundo fator as quatro pressões de serviço $(\mathrm{P} 1=70 \mathrm{kPa}, \mathrm{P} 2=140$ $\mathrm{kPa}, \mathrm{P} 3=210 \mathrm{kPa}$ e $\mathrm{P} 4=280 \mathrm{kPa}$ ) com três repetições (três linhas laterais por tipo de gotejador em cada unidade gotejadora).

Os modelos de regressão foram escolhidos com base na significância dos coeficientes de regressão, aplicando-se o teste t em um nível de até 10\%, no coeficiente de determinação ( $\geq 60 \%$ ) e no processo em estudo.

\section{RESULTADOS E DISCUSSÃO}

Analisando a Figura 2, verificou-se que a obstrução variou tanto em função do tipo de emissor, pelas diferenças nas características (Tabela 1), quanto da pressão de serviço utilizada, onde as maiores pressões provavelmente interferem na sedimentação de sólidos suspensos e na adesão de micro-organismos no interior dos emissores e das linhas laterais, conforme evidenciado por Silva et al. (2016) em seu estudo com unidades gotejadoras que aplicaram água residuária da castanha de caju. 
A.

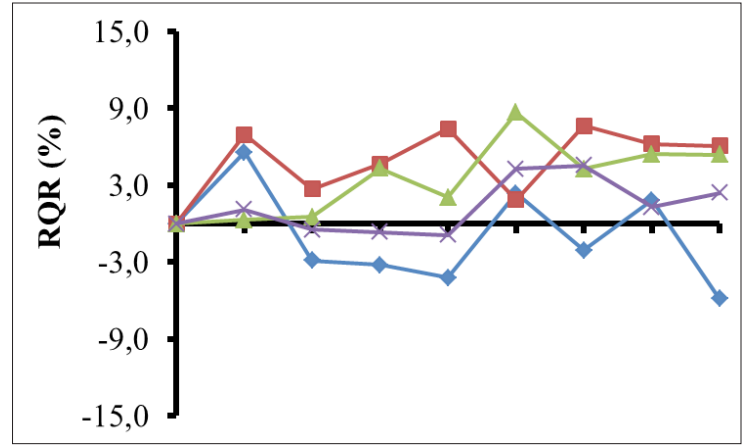

B.

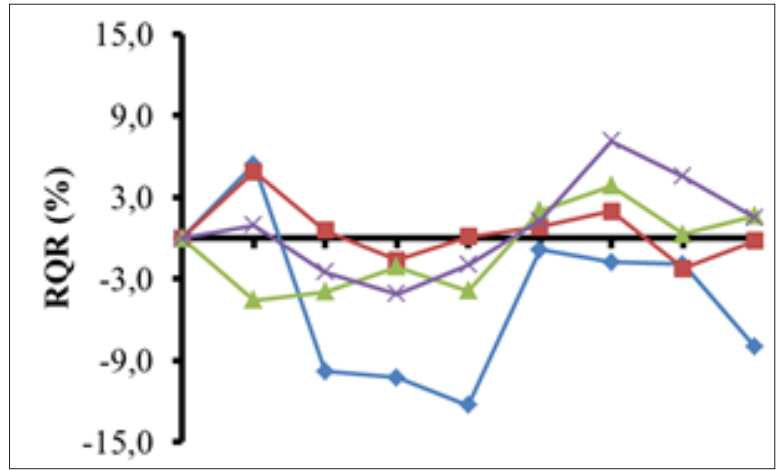

C.

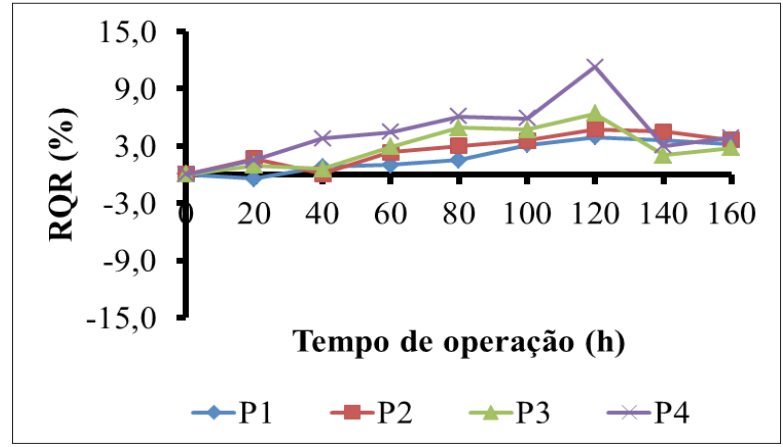

Figura 2. Valores médios da redução da vazão relativa (RQR) nas unidades gotejadoras dotadas dos emissores G1 (A), G2 (B) e G3 (C), operando nas pressões de serviço P1 (70 kPa), P2 (140 kPa), P3 $(210 \mathrm{kPa})$ e $\mathrm{P} 4(280 \mathrm{kPa})$ com percolado de aterro sanitário diluído, durante $160 \mathrm{~h}$. 
Segundo Mesquita et al. (2016a), valores de RQR superiores a zero (RQR $>0)$ indicam entupimento dos gotejadores que ocasiona redução da vazão dos emissores, enquanto valores de $\mathrm{RQR}$ inferiores a zero $(\mathrm{RQR}<0)$ evidenciam obstrução dos gotejadores em função do aumento da vazão dos emissores. Neste sentido, notou-se que os gotejadores não autocompensantes (G1 e G2) apresentaram ao longo do período experimental redução e aumento de suas respectivas vazões, em função da formação de biofilme no labirinto. $\mathrm{O}$ aumento da vazão foi mais pronunciado quanto às unidades gotejadoras operaram com a menor pressão de serviço $(\mathrm{P} 1=70 \mathrm{kPa})$, pois nesta condição existe mais suscetibilidade ao entupimento, corroborando com o estudo de Silva et al. (2013).

Ao final dos ensaios experimentais ( $160 \mathrm{~h}$ ), ocorreram valores médios de RQR de -6, 6, 5 e $2 \%$ para o gotejador G1 (Figura 2A) operando nas pressões de serviço P1, P2, P3 e P4, respectivamente. Na Figura 2B constatou-se que os valores de RQR, do gotejador G2, foram de $-8 \%$ na pressão de serviço $\mathrm{P} 1,0 \%$ na pressão de serviço P2 e $2 \%$ nas pressões de serviço P3 e P4. Para o gotejador G3 (Figura 2C), observaram-se valores de RQR iguais a 3\% nas unidades gotejadoras submetidas às pressões de serviço $\mathrm{P} 1$ e $\mathrm{P} 3$ e a $4 \%$ naquelas submetidas às pressões de serviço P2 e P4. No trabalho de Mesquita et al. (2016a), o gotejador não autocompensante que aplicou, percolado de aterro sanitário diluído durante $160 \mathrm{~h}$, apresentou valores máximos de RQR entre 20 e 30\% superiores ao do presente estudo, nos tempos de operação de 40 e $100 \mathrm{~h}$.

Observou-se que houve aumento da vazão atual do gotejador G1 (RQR $<0)$ ao longo de todo o período experimental, submetido às pressões de serviço P1 e P4, do gotejador G2 em todas as pressões de serviço e do gotejador G3 na pressão de serviço P1. No entanto, o gotejador G2 quando submetido à pressão de serviço P1 destacou-se dos demais, apresentando aumento de vazão de $12 \%$ no tempo de operação de $80 \mathrm{~h}$. Esse fato pode ser explicado pelo acúmulo de biofilme, nas paredes do labirinto dos gotejadores, diminuindo a área de passagem e aumentando a pressão do fluxo do efluente no labirinto, elevando, consequentemente, a vazão do emissor. Outra explicação seriam as falhas do diafragma, atribuindo-as à deterioração da membrana por ação de atividade microbiana, confirmando os relatos de Ravina et al. (1992) e Cararo et al. (2006).

$\mathrm{O}$ indicador de desempenho hidráulico APQ (Figura 3) refere-se à porcentagem de gotejadores, da unidade gotejadora, que apresentaram aumento de vazão 
dentro da faixa de 10 a $49 \%$ do valor da vazão inicial, conforme proposto por Ravina et al. (1992). O maior valor de APQ foi notado para o gotejador G2 operando na pressão de serviço P1, em que $83 \%$ dos emissores G2 da unidade gotejadora apresentaram aumento de vazão de 10 a 49\% do valor da vazão inicial, no tempo de operação de 80 h. Resultados encontrados por Ravina et al. (1992) demonstraram que ocorreram valores de APQ variando de 0 a $24 \%$ em 12 tipos de gotejadores que operaram com água residuária doméstica tratada.

Notou-se que a alteração de APQ ocorreu, apenas, nos gotejadores não autocompensantes (G1 e G2 das Figuras 3A e 3B); fato este atribuído a acumulação excessiva de biofilme no labirinto de alguns emissores, ocasionando entupimento parcial e total e, consequentemente, aumento da pressão de serviço e da vazão média destes emissores. Por outro lado, o gotejador G3 (Figura 3C) não apresentou valores de APQ, indicando maior resistência ao entupimento em relação aos emissores G1 e G2, por possuir maior vazão nominal e menor comprimento de labirinto, conforme relatado por Mesquita et al. (2016a).

A.

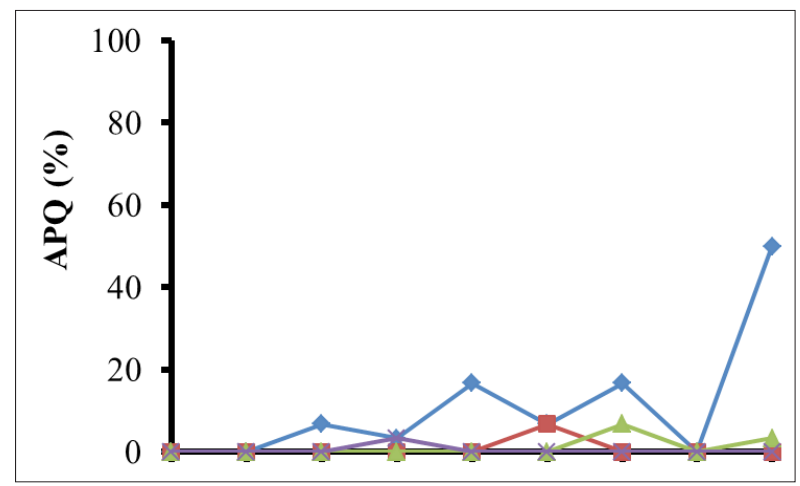


B.

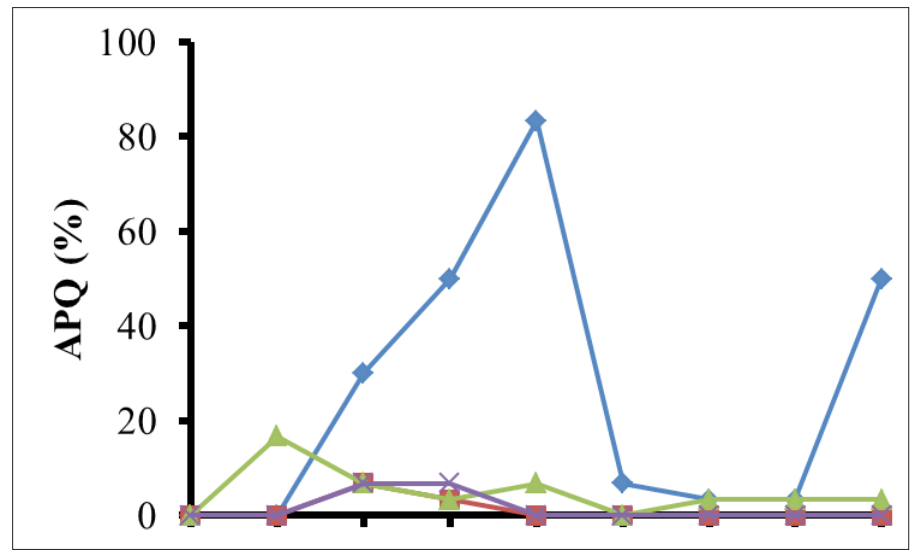

C.

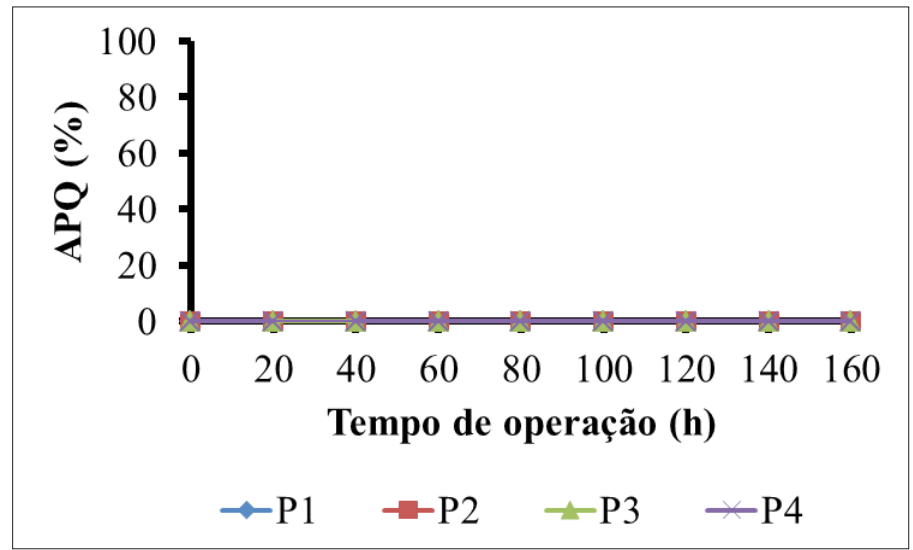

Figura 3. Valores médios do aumento parcial de vazão (APQ) nas unidades gotejadoras dotadas dos emissores G1 (A), G2 (B) e G3 (C), operando nas pressões de serviço P1 (70 kPa), P2 (140 kPa), P3 $(210 \mathrm{kPa})$ e $\mathrm{P} 4(280 \mathrm{kPa})$ com percolado de aterro sanitário diluído, durante $160 \mathrm{~h}$.

Observou-se que, para o gotejador G1 (Figura 3A) houve oscilações nos valores de APQ nas unidades gotejadoras submetidas às pressões de serviço P1 e P3; assim como para o gotejador G2 (Figura 3B), das unidades gotejadoras submetidas às pressões de serviço $\mathrm{P} 1, \mathrm{P} 3$ e $\mathrm{P} 4$, em virtude da formação de biofilme no interior dos emissores. Enquanto que nas demais combinações entre tipos de gotejadores e pressões de serviço os valores de APQ permaneceram nulos, durante o período de 
operação do sistema. Em relação ao gotejador G3, a maior resistência ao entupimento segundo Mesquita et al. (2016a), está relacionada ao mecanismo de auto-limpeza inerente ao tipo de emissor, devido à atuação da membrana de autocompensação.

$\mathrm{O}$ indicador de desempenho hidráulico RPQ (Figura 4) refere-se à porcentagem de gotejadores presentes na unidade gotejadora que apresentaram redução de vazão de 10 a 49\% do valor da vazão inicial, como proposto por Ravina et al. (1992). Em geral, a RPQ é ocasionada pela formação de biofilme no labirinto dos emissores, acarretando redução na área de escoamento e, consequentemente, redução na vazão. Segundo Mesquita et al. (2016a), gotejadores não autocompensantes, com maior comprimento do labirinto que aplicam água residuária, favorecem tanto a sedimentação de partículas quanto a adesão de bactérias com parede celular hidrofóbica, resultando no desenvolvimento de biofilme.

A.

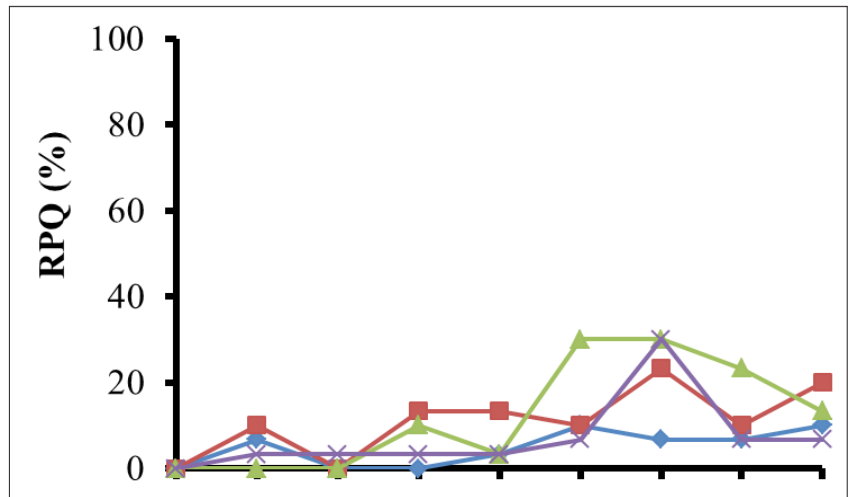


B.

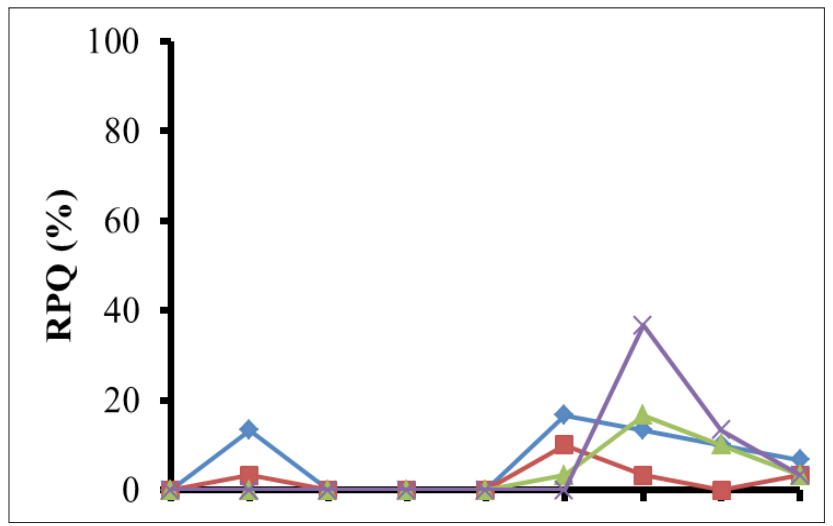

C.

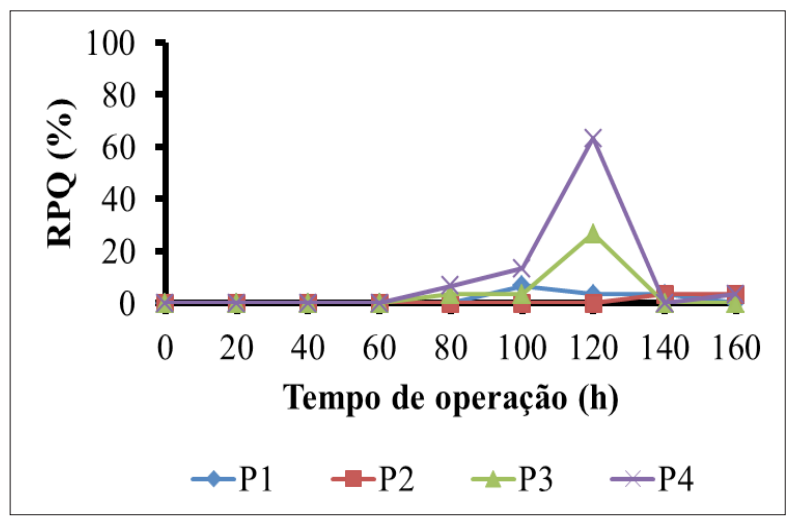

Figura 4. Valores médios da redução parcial de vazão (RPQ) nas unidades gotejadoras dotadas dos emissores G1 (A), G2 (B) e G3 (C), operando nas pressões de serviço P1 (70 kPa), P2 (140 kPa), P3 $(210 \mathrm{kPa})$ e $\mathrm{P} 4(280 \mathrm{kPa})$ com percolado de aterro sanitário diluído, durante $160 \mathrm{~h}$.

Evidenciou-se que o gotejador G3 (Figura 4C), quando submetido à pressão de serviço P4, apresentou valor médio de RPQ constante e igual a $0 \%$, até o tempo de operação de 60 h. Após esse período, houve oscilação de 0\% (60 h) para 63\% $(120 \mathrm{~h})$, reduzindo novamente para $0 \%(140 \mathrm{~h})$. Este fato pode ser atribuído à desobstrução espontânea dos gotejadores devido ao aumento de temperatura durante determinado período, acarretando o desprendimento do biofilme das paredes do labirinto (CUNHA et al., 2006), como, também, à sobrelevação da pressão de serviço ocorrida em função da obstrução parcial e total dos gotejadores, como evidenciado 
por Faria et al. (2002). No entanto, esse mesmo gotejador (G3) apresentou as menores oscilações nos valores do RPQ, obtendo valores máximos de 7 e 3\% nos tempos de 100 e $140 \mathrm{~h}$, para as unidades gotejadoras, submetidas às pressões de serviço P1 e P2, respectivamente, devido a sua maior resistência ao entupimento por ser autocompensante.

Para o tempo de funcionamento inicial $(0 \mathrm{~h})$, os gotejadores de todas as unidades gotejadoras apresentaram valores de RPQ igual a $0 \%$. Contudo, no tempo de funcionamento final (160 h), o gotejador G1 (Figura 4A) apresentou valores médios de RPQ iguais a 10, 20, 13 e 7\% nas unidades gotejadoras submetidas às pressões de serviço P1, P2, P3 e P4, respectivamente. Para o gotejador G2 (Figura 4B), os valores médios de RPQ foram de 7\% na pressão de serviço P1 e de 3\% nas pressões de serviço P2, P3 e P4. Observa-se que os valores médios de RPQ foram de $0 \%$ no gotejador G3 (Figura 4C) das unidades gotejadoras que operaram nas pressões de serviço P1 e $\mathrm{P} 3$, enquanto que, nas unidades gotejadoras submetidas às pressões de serviço $\mathrm{P} 2 \mathrm{e}$ P4, os valores de RPQ foram de 3\% para o gotejador G3. No trabalho realizado por Ravina et al. (1992) constataram-se valores de RPQ oscilando de 0 a 49\% em 12 tipos de gotejadores que operaram com água residuária doméstica tratada.

Os resultados do desempenho hidráulico, apresentados nas Figuras 2, 3 e 4, indicaram que o emissor G2, operando na pressão de serviço P1, foi mais suscetível ao entupimento, devido ao maior comprimento do labirinto, que favorece o desenvolvimento de biofilme nos trechos de menor velocidade de escoamento do efluente, confirmando os relatos de Cararo et al. (2006) e Dazhuang et al. (2009), como, também, ao fato da pressão de serviço a qual esteve submetido (70 $\mathrm{kPa})$ ser inferior à faixa de pressão recomendada pelo fabricante de 100 a $300 \mathrm{kPa}$ (Tabela 1). O gotejador G1 foi mais suscetível ao entupimento do que o gotejador G3, por apresentar menor vazão, e menos suscetível ao entupimento do que G2, devido ao menor comprimento do labirinto. Os menores níveis de entupimento ocorreram no gotejador G3 das unidades gotejadoras, submetidas às pressões de serviço P1 e P2.

$\mathrm{Na}$ Tabela 2 constam as equações de regressão que melhor representaram os dados do RQR em função do tempo de operação (T), para as combinações entre tipos de gotejadores $(\mathrm{G})$ e pressões de serviço $(\mathrm{P})$. 
Tabela 2. Equações de regressão ajustadas à variável redução da vazão relativa (RQR) em função dos tempos de operação $(\mathrm{T})$, das unidades gotejadoras, para as combinações entre tipos de gotejadores $(\mathrm{G})$ e pressões de serviço $(\mathrm{P})$

\begin{tabular}{cclc}
\hline Combinação & Especificação & Equação de regressão & $\mathbf{R}^{2}$ \\
\hline 1 & $\mathrm{G} 1 \times \mathrm{P} 1$ & $\mathrm{RQR}=-0,953$ & - \\
2 & $\mathrm{G} 1 \times \mathrm{P} 2$ & $\mathrm{RQR}=4,833$ & 0,60 \\
3 & $\mathrm{G} 1 \times \mathrm{P} 3$ & $\mathrm{RQR}=0,181+0,0406^{* *} \mathrm{~T}$ & - \\
\hline 4 & $\mathrm{G} 1 \times \mathrm{P} 4$ & $\mathrm{RQR}=1,282$ & - \\
\hline 5 & $\mathrm{G} 2 \times \mathrm{P} 1$ & $\mathrm{RQR}=-4,395$ & - \\
6 & $\mathrm{G} 2 \times \mathrm{P} 2$ & $\mathrm{RQR}=0,140$ & 0,60 \\
7 & $\mathrm{G} 2 \times \mathrm{P} 3$ & $\mathrm{RQR}=-0,553-1,172^{0} \mathrm{~T}^{0,5}+0,116^{*} \mathrm{~T}$ & - \\
\hline 8 & $\mathrm{G} 2 \times \mathrm{P} 4$ & $\mathrm{RQR}=0,756$ & 0,84 \\
\hline 9 & $\mathrm{G} 3 \times \mathrm{P} 1$ & $\mathrm{RQR}=-0,481+0,0282^{* *} \mathrm{~T}$ & 0,77 \\
11 & $\mathrm{G} 3 \times \mathrm{P} 2$ & $\mathrm{RQR}=0,367+0,0279^{* *} \mathrm{~T}$ & 0,67 \\
\hline 12 & $\mathrm{G} 3 \times \mathrm{P} 3$ & $\mathrm{RQR}=-0,919+0,103^{*} \mathrm{~T}-0,496^{*} \mathrm{~T}^{2}$ & 0,60 \\
\hline
\end{tabular}

Nota: ${ }^{* *},{ }^{*} \mathrm{e}^{0}$ significativos a 1,5 e $10 \%$ de probabilidade, respectivamente, pelo teste $\mathrm{t}$.

Os modelos de regressão raiz quadrada e quadrático foram os que melhor se ajustaram à relação entre os dados de RQR e T das unidades gotejadoras com a combinação 7 (G2 x P3) e 11 (G3 x P3) e 12 (G3 x P4), respectivamente. Enquanto o modelo linear foi o que melhor se ajustou à relação entre os dados de RQR e T das unidades gotejadoras para as combinações 9 (G3 x P1), 10 (G3 x P2) e 3 (G1 x $\mathrm{P} 3$ ). Nos modelos lineares, os valores que multiplicam a variável T são denominados coeficientes angulares, assim quanto maior o valor deste coeficiente maior a taxa de entupimento no gotejador. Os coeficientes angulares apresentados na Tabela 2 indicaram que a taxa de entupimento nas combinações 9 (G3 x P1) e 10 (G3 x P2) são semelhantes, entretanto a taxa de entupimento na combinação 3 (G1 x P3) foi maior. Nas combinações onde foram ajustadas equações de regressão evidenciou-se maior suscetibilidade ao entupimento, devido à menor vazão do gotejador não autocompensante (G1) e as menores resistências impostas pelo escoamento do efluente nos menores valores de pressão de serviço (P1 e P2). Estes resultados diferem dos encontrados por Mesquita et al. (2016a), que ajustaram apenas o modelo de regressão linear, aos dados de RQR em função de T, em unidade gotejadora aplicando percolado 
de aterro sanitário diluído sob pressão de serviço de $140 \mathrm{kPa}$. Já as combinações 1 (G1 x P1), 5 (G2 x P1), 2 (G1 x P2), 6 (G2 x P2), 4 (G1 x P4) e 8 (G2 x P4) não apresentaram efeito significativo do $T$ sobre $R Q R$, indicando que a média foi o modelo que melhor se ajustou aos dados, em função dos menores níveis de entupimento.

\section{CONCLUSÕES}

A aplicação de percolado diluído por gotejamento pode possibilitar a produção de gramíneas, nas células do aterro sanitário, ocorrendo assim a recirculação do percolado que minimiza a contaminação do solo e das águas superficiais e subterrâneas.

Os gotejadores não autocompensantes (Plastro Hydrodrip Super e Netafim Tiran) apresentaram maiores níveis de entupimento em relação ao gotejador autocompensante (Netafim PCJ-CNJ).

Houve atenuação do entupimento quando o gotejador Netafim PCJ-CNJ operou com percolado diluído nas pressões de serviço de 70 e $140 \mathrm{kPa}$.

\section{REFERÊNCIAS}

ASSOCIAÇÃO BRASILEIRA DE NORMAS TÉCNICAS (ABNT). Equipamentos de irrigação agrícola - Emissores e tubos emissores - Especificações e métodos de ensaio. ABNT NBR ISO 9261. São Paulo: ABNT, 2006. 17p.

CARARO, D. C.; BOTREL, T. A.; HILLS, D. J.; LEVERENZ, H. L. Analysis of clogging in drip emitters during wastewater irrigation. Applied Engineering in Agriculture, $v$. 22, n. 2, p. 251-257, 2006.

CEARÁ. Resolução COEMA no 2 de 2 de fevereiro de 2017. Dispõe sobre padrões e condições para lançamento de efluentes líquidos gerados por fontes poluidoras, revoga as Portarias SEMACE $n^{\circ} 154$, de 22 de julho de 2002 e $n^{\circ} 111$, de 05 de abril de 2011, e altera a Portaria SEMACE n ${ }^{0}$ 151, de 21 de fevereiro de 2017. Diário Oficial do Estado do Ceará, Fortaleza, 2002. Disponível em: < https://www.legisweb. 
com.br/legislacao/?id=337973> . Acesso em: 28 mai. 2017.

COELHO, D. C. L.; BATISTA, R. O.; SILVA, P. C. M.; MESQUITA, F. O. Produção de capim elefante utilizando percolado de aterro sanitário. Bioscience Journal, v. 31, n. 3, p. 830-840, 2015.

COELHO, D. C. L.; BATISTA, R. O.; MESQUITA, F. O.; SILVA, K. B.; ALVES, S. M. C.; GURGEL, M. T. Trace elements in Ultisol irrigated with landfill leachate and public-supply water. Revista Brasileira de Engenharia Agrícola e Ambiental, v. 20, n. 8, p. $769-774,2016$.

CUNHA, F. F.; MATOS, A. T.; BATISTA, R. O.; LO MONACO, P. A. Uniformidade de distribuição em sistemas de irrigação por gotejamento utilizando água residuária da despolpa dos frutos do cafeeiro. Acta Scientiarum. Agronomy, v. 28, n. 1, p. 143-147, 2006.

CUNHA, M. E.; MARQUES, B. C. D.; BATISTA, R. O.; COSTA, A. G.; CUNHA, R. R.; ANDRADE, A. T. S. Obstrução de gotejadores operando com efluente de laticínios diluído. Revista Brasileira de Agricultura Irrigada, v. 11, n. 4, p. 1517-1527, 2017.

DAZHUANG, Y.; ZHIHUI, B.; ROWAN, M.; LIKUN, G.; SHUMEI, R.; PEILING, Y. Biofilm structure and its influence on clogging in drip irrigation emitters distributing reclaimed wastewater. Journal of Environmental Sciences, v. 21, n. 6, p. 834-841, 2009.

EL-SALAM, M. M. A.; ABU-ZUID, G. I. Impact of landfill leachate on the groundwater quality: A case study in Egypt. Journal of Advanced Research, v. 6, n. 4, p. 579-586, 2015.

FARIA, L. F.; COELHO, R. D.; FLECHA, P. A. N.; ROBLES, W. G. R.; VÁSQUEZ, M. A. N. Entupimento de gotejadores e seu efeito na pressão da rede hidráulica de um sistema de microirrigação. Revista Brasileira de Engenharia Agrícola e Ambiental, v. 6, n. 2, p. 195-198, 2002.

FERNANDES, R. K. A.; BATISTA, R. O.; SILVA, S. K. C.; OLIVEIRA, J. F.; PAIVA, L. A. L. Vazão de gotejadores aplicando água residuária da castanha de caju. Irriga, Botuca- 
tu, v. 19, n. 4, p. 585-597, 2014.

GOMES, L. P.; KOHL, C. A.; SOUZA, C. L. L.; REMPEL, N.; MIRANDA, L. A. S.; MORAES, C. A. M. Avaliação ambiental de aterros sanitários de resíduos sólidos urbanos precedidos ou não por unidades de compostagem. Engenharia Sanitária e Ambiental, v. 20, n. 3, p. 449-462, 2015.

LI, J.; WEN, J. Effects of water managements on transport of $E$. coli in soil-plant system for drip irrigation applying secondary sewage effluent. Agricultural Water Management, v. 178, n. 8, p. 12-20, 2016.

MARQUES, B. C. D.; CUNHA, V. T.; CUNHA, V. T.; SILVA, K. B.; BATISTA, R. O. Desempenho de gotejadores operando com água residuária de laticínios em escala laboratorial. Irriga, v. 21, n. 1, p. 140-155, 2016.

MATOS, A. T.; SILVA, D. F.; LO MONACO, P. A. V.; PEREIRA, O. G. Produtividade e composição química do capim-Tifton 85 submetido a diferentes taxas de aplicação do percolado de resíduo sólido urbano. Engenharia Agrícola, v. 33, n. 1, p. 188$200,2013$.

MESQUITA, F. O.; ALVES, S. M. C.; BATISTA, R. O.; DANTAS, T. B.; DI SOUZA, L. Desempenho de gotejadores aplicando percolado de aterro sanitário diluído. Irriga, v. 21, n. 1, p. 156-171, 2016a.

MESQUITA, F. O.; ALVES, S. M. C.; BATISTA, R. O.; DANTAS, T. B.; DI SOUZA, L. Drip units operating with dilute landfill leachate. Revista Caatinga, v. 29, n. 1, p. 163172, 2016b.

MOODY, C. M.; TOWNSEND, T. G. A comparison of landfill leachates based on waste composition. Waste Management, v. 63, n. 3, p. 267-274, 2017.

RAVINA, I.; PAZ, E.; SOFER, Z.; MARCU, A.; SHISHA, A.; SAGI, G. Control of emitter clogging in drip irrigation with reclaimer wastewater. Irrigation Science, v. 13, n. 3, p. 129-139, 1992.

SILVA, K. B.; SILVA JÚNIOR, M. J.; BATISTA, R. O.; SANTOS, D. B.; BARBOSA FILHO, $\mathrm{S}$. Desempenho de gotejadores operando com efluente da castanha de caju sob dis- 
tintas pressões de serviço. Revista Ceres, v. 60, n. 3, p. 339-346, 2013.

SILVA, K. B.; BATISTA, R. O.; MESQUITA, F. O.; COELHO, D. C. L.; SANTOS, W. O. Empirical models for performance of drippers applying cashew nutprocessing waste water. Revista Caatinga, v. 29, n. 2, p. 405-414, 2016.

Recebido em: 25/03/2017 Aceito em: 01/10/2017 